\title{
A pilot randomized controlled trial comparing THUNDERBEAT to the Maryland LigaSure energy device in laparoscopic left colon surgery
}

\author{
Jeffrey W. Milsom ${ }^{1} \cdot$ Koianka Trencheva $^{1}$ (D) Kota Momose ${ }^{1} \cdot$ Miroslav P. Peev $^{1} \cdot$ Paul Christos $^{2} \cdot$ Parul J. Shukla $^{1}$. \\ Kelly Garrett ${ }^{1}$
}

Received: 22 February 2021 / Accepted: 4 October 2021 / Published online: 1 November 2021

(c) The Author(s) 2021

\begin{abstract}
Background The THUNDERBEAT is a multi-functional energy device which delivers both ultrasonic and bipolar energy, but there are no randomized trials which can provide more rigorous evaluation of the clinical performance of THUNDERBEAT compared to other energy-based devices in colorectal surgery. The aim of this study was to compare the clinical performance of THUNDERBEAT energy device to Maryland LigaSure in patients undergoing left laparoscopic colectomy.

Methods Prospective randomized trial with two groups: Group 1 THUNDERBEAT and Group 2 LigaSure in a single university hospital. 60 Subjects, male and female, of age 18 years and above undergoing left colectomy for cancer or diverticulitis were included. The primary outcome was dissection time to specimen removal (DTSR) measured in minutes from the start of colon mobilization to specimen removal from the abdominal cavity. Versatility (composite of five variables) was measured by a score system from 1 to 5 ( 1 being worst and 5 the best), and adjusted/weighted by coefficient of importance with distribution of the importance as follow: hemostasis 0.275 , sealing 0.275 , cutting 0.2 , dissection 0.15 , and tissue manipulation 0.1 . Other variables were: dryness of surgical field, intraoperative and postoperative complications, and mortality. Follow-up time was 30 days.

Results 60 Patients completed surgery, 31 in Group 1 and 29 in Group 2. There was no difference in the DTSR between the groups, $91 \mathrm{~min}$ vs. $77 \mathrm{~min}(p=0.214)$. THUNDERBEAT showed significantly higher score in dissecting and tissue manipulation in segment 3 (omental dissection), and in overall versatility score $(p=0.007)$ as well as versatility score in Segment 2 (retroperitoneal dissection $p=0.040)$ and Segment $3(p=0.040)$. No other differences were noted between the groups.

Conclusions Both energy devices can be employed effectively and safely in dividing soft tissue and sealing mesenteric blood vessels during laparoscopic left colon surgery, with THUNDERBEAT demonstrating some advantages over LigaSure during omental dissection and tissue manipulation.
\end{abstract}

ClinicalTrial.gov \# NCT02628093.

Keywords THUNDERBEAT $\cdot$ Surgery $\cdot$ Energy devices

Jeffrey Milsom and Koianka Trencheva have equal contribution to this manuscript.

This study has been accepted as a poster at ASCRS 2019.

Jeffrey W. Milsom

jwm2001@med.cornell.edu

1 Section of Colorectal Surgery, Department of Surgery, Weill Cornell Medicine College, New York, NY 10065, USA

2 Division of Biostatistics and Epidemiology, Department of Healthcare Policy \& Research, Weill Cornell Medicine, New York, NY, USA
The growing use of laparoscopic surgery for benign and malignant colorectal diseases during the last two decades has prompted development of new small caliber $(5 \mathrm{~mm})$ electrosurgical instruments for safe and effective hemostasis, vessel sealing, and tissue dissection [1-3]. Furthermore, the aim of these energy devices has also been to shorten operative time, lessen the thermal spread, and reduce the need for instrument exchange. The currently available energy devices used during laparoscopic colorectal surgery utilize three different energy-based methods: monopolar (ME), bipolar (BE) and ultrasonically activated electrosurgery (UAS) (4-Milsom). Amongst the most generally available 
energy devices in the USA are LigaSure ${ }^{\mathrm{TM}}$ and Sonicision, Medtronic, USA; Harmonic Ace, Ethicon Endo-Surgery, USA; and THUNDERBEAT (TB), Olympus, Japan. All are insertable into the abdominal cavity via $5 \mathrm{~mm}$ port. The TB is a multi-functional energy device which delivers simultaneously ultrasonic and bipolar energy. This allows surgeons to seal and safely divide blood vessels up to $7 \mathrm{~mm}$, cut and dissect omental and mesentery tissue, and potentially reduce the need for instrument exchange $[2,4,5]$. UAS devices are multi-functional similarly to TB, but are approved to only seal vessels up to $4-5 \mathrm{~mm}$ in diameter $[6,7]$. Bipolar electrosurgical technology has been widely used in laparoscopic bowel resection and considered a safe method for dissection and vessel ligation [1, 8-10]. Recent studies comparing TB to other energy devices suggest that all are safe and effective to use in laparoscopic colorectal surgery and report similar intraoperative and postoperative outcomes [2, 11, 12]. However, most of these studies are retrospective cohort studies or small prospective cohorts. There are no randomized controls trials which can provide more rigorous evaluation of the clinical performance of TB compared to other energy-based devices in laparoscopic colorectal surgery.

\section{Aims/objective}

The aim of this randomized trial was to compare the clinical performance between the THUNDERBEAT and Maryland LigaSure Energy Devices in performing soft tissue dissection, dividing and sealing blood vessels in patients undergoing left laparoscopic colectomy.

\section{Materials and methods}

\section{Study design}

This was a pilot prospective randomized trial in a single academic institution. Patients undergoing laparoscopic left colectomy for their medical condition were randomized with equal chances into one of two groups: Group 1-THUNDERBEAT and Group 2-LigaSure. After randomization, the study involved prospective data collection before, during and after surgery and video recording of the surgery. All surgeries were carried out according to the regular surgical and anesthesia care. The follow up after surgery was 30 days. The study was approved by the Institutional Review Board.

\section{Population}

Sixty patients, male and female, age 18 years and above and American Society of Anesthesiologists (ASA) class between 1 and 3, undergoing elective left laparoscopic colectomy for neoplasm or diverticulitis, were included in the study after providing research informed consent. Patients with morbid obesity (body mass index, BMI $>35$ ), multiple previous abdominal surgeries, on anticoagulants prior to surgery, coagulopathy disorders, pregnant women, and those to whom electrosurgery is contraindicated were excluded from the study.

\section{Outcomes}

The primary outcomes were: (1) dissection time to specimen removal (DTSR), and (2) versatility score. The primary outcome DTSR was defined as time to specimen removal measured in minutes from the start of colon mobilization to specimen removal from the abdominal cavity. Versatility (composite of five variables) was measured by a score system from 1 to 5 ( 1 being worst and 5 the best) for each of the six specific segments (Fig. 1) and adjusted/weighted by coefficient of importance with distribution of the importance as follow: hemostasis 0.275 , sealing 0.275 , cutting 0.2 , dissection 0.15 , and tissue manipulation 0.1 . A mean score of 3.5 and above was considered a high versatility and below 3.5 and lower as low versatility (4). The overall versatility score is presented as an average of the mean versatility scores from each of the six surgical segments each evaluated using the score displayed on Table 1 . The Versatility score was developed before the trial and based on the surgeon's experience about the relative importance of the five variables included in the versatility score.

The ease of use of instruments was evaluated with a survey evaluating the surgeon's opinion on the instrument immediately after surgery consisting of 8 questions on the scale from 1 to 10 , where a score of 1 is worst and 10 is the best (Table 2). The secondary outcome, drier surgical field was an evaluation of the entire surgical field for overall oozing of blood or any other body fluids using a scoring system from 1 to 5 as described on Table 3.

Other outcome data collected were failure of the energy instruments to control bleeding, complications related to use of the instrument, visible thermal spread, postoperative bleeding requiring intervention, thermal injuries manifestation after surgery, reoperation, readmission, length of hospital stay and mortality. Patients were assessed daily after surgery until discharge and at 30 days following surgery.

\section{Study instruments}

\section{THUNDERBEAT $5 \mathrm{~mm}$ to $35 \mathrm{~cm}$ (Olympus, Japan)}

The TB device has been cleared under $510(\mathrm{~K})$ by FDA and currently used for regular care. The surgeons were able to coagulate blood vessels up to $7 \mathrm{~mm}$, cut and dissect during surgery. The device consists of: THUNDERBEAT device 


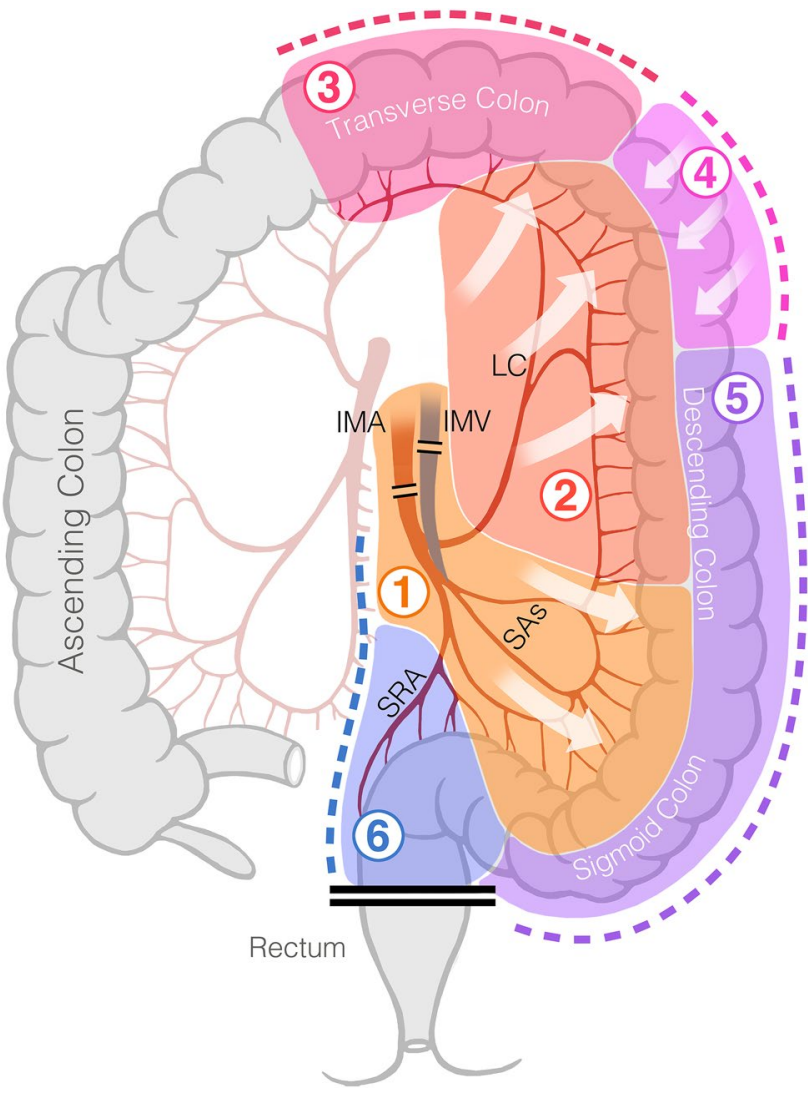

Fig. 1 Description of the left colectomy study segments. Segment 1: dissection/division of IMA pedicle - division on or around IMA/ IMV and within 2-3 cm of main vessels of mesentery (including window). Segment 2: retroperitoneal dissection-dissection in retroperitoneum above and below IMA/IMV, above the sigmoid up to splenic flexure posteriorly. Segment 3: omental dissection/resectionseparation of omentum and mobilization of transverse colon up to the splenic flexure (not including splenic flexure). Segment 4: splenic flexure takedown - take down of splenic flexure with complete separation of it from retroperitoneum. Segment 5: lateral colonic dissection-lateral freeing up of sigmoid and left colon to everything below splenic flexure. Segment 6: mesenteric and pelvic dissection. IMA inferior mesenteric artery, $I M V$ inferior mesenteric vein, $S A s$ sigmoid arteries, $L C$ left colic artery, $S R A$ superior rectal artery

and generator (Fig. 2a). The device is provided sterile and intended for single use only. The generators settings were the same for all cases in this study.

\section{Maryland LigaSure ${ }^{\mathrm{TM}} 5 \mathrm{~mm}$ to $37 \mathrm{~cm}$ (Medtronic, USA)}

Maryland LigaSure device is an FDA approved device and currently is used throughout the USA in surgery for tissue dissection and vessel ligation. The device consists of the LigaSure device and Generator-Force Triad (Fig. 2b). The device is provided sterile and intended for single use only.

All participating surgeons were trained in using TB and Maryland LigaSure devices as they are used daily for regular surgical care, and surgeons used the devices on at least 10 patients prior to this study.

\section{Equipment}

All surgeries were performed using the same laparoscopic equipment from Olympus and all cases were recorded with the Olympus video recording systems. The equipment included, High Definition LCD Monitor, Xenon Light Source, C02 Insufflator, laparoscopic camera 5 Endoeye Flex Deflectable scope, and Video System Center. Also, for all study cases the same THUNDERBEAT and Force Triad Generator were used with preset mode.

\section{Statistical considerations}

Blocked randomization using the method of random permuted blocks was used in the trial. A series of randomized blocks of four was generated with a 1:1 allocation ratio to allow for an equal number of patients in the two groups, by independent statistician to minimize bias. Group status was defined by the two different instruments: Group 1 THUNDERBEAT and Group 2 LigaSure. The randomization was generated by a biostatistician, and subjects were assigned to the groups at the start of the surgery using randomization envelopes.

This study was designed as a pilot (exploratory) randomized study. Because at the time this study was planned there were no other studies in colorectal surgery evaluating THUNDERBEAT that could have been used for estimation of dissection time, the study was not powered to detect a specific difference in DTSR between the groups. Post hoc analysis was performed to compare the primary outcome DTSR between the groups.

The primary outcome DTSR between the groups was evaluated using Wilcoxon rank-sum test. Demographic, preoperative, and postoperative variables were compared between groups by the Wilcoxon rank-sum test for continuous variables and the $\chi^{2}$ test/Fisher's exact test for categorical variables, as appropriate. The versatility score was calculated as defined. The surgeon's opinion evaluation survey is presented as number and percentages, and then compared between the two instrument groups. All $p$-values are twosided with statistical significance at the $0.05 \alpha$ level. All analyses were performed in IBM SPSS Version 25 (Armonk, NY: IBM Corp).

\section{Results}

For presenting the result in this manuscript, we used the CONSORT (Consolidated Standards of Reporting Trials) protocol guidance for more transparency and better quality 
Table 1 Versatility variables evaluation

\begin{tabular}{|c|c|c|c|}
\hline Variable score & Variable definition & $\begin{array}{l}\text { THUN- } \\
\text { DER- } \\
\text { BEAT }\end{array}$ & LigaSure \\
\hline Hemostasis & Definition of score & & \\
\hline 5 & No bleeding at vessel or tissue site & 5 & 5 \\
\hline 4 & Mild blood oozing at tissue site; no intervention needed & 4 & 4 \\
\hline 3 & Moderate blood oozing at tissue site requiring intervention & 3 & 3 \\
\hline 2 & Heavy bleeding requiring immediate further intervention & 2 & 2 \\
\hline 1 & No hemostasis achieved with the instrument after two attempts & 1 & 1 \\
\hline \multicolumn{4}{|c|}{$\begin{array}{l}\text { Sealing at surgery } \\
\text { (visual score by } \\
\text { surgeon) }\end{array}$} \\
\hline 5 & Complete seal using instrument 1 or 2 applications only on the named vessels & 5 & 5 \\
\hline 4 & Complete seal but using instrument $>2$ and $<4$ times to seal the named vessels & 4 & 4 \\
\hline 3 & Complete seal using instrument 4 and $>4$ application less than 6 on the named vessels & 3 & 3 \\
\hline 2 & Incomplete seal even after more than 6 applications on the named vessels & 2 & 2 \\
\hline 1 & Incomplete seal, has to use another instrument to seal the named vessel & 1 & 1 \\
\hline \multicolumn{4}{|l|}{ Cutting } \\
\hline 5 & Complete tissue transection & 5 & 5 \\
\hline 4 & Tissue transection but minor tissue strand remaining, not requiring reapplication of device & 4 & 4 \\
\hline 3 & Tissue transection but tissue strand remaining requiring reapplication of device & 3 & 3 \\
\hline 2 & Incomplete tissue transection multiple reapplication of device & 2 & 2 \\
\hline 1 & No transection/cutting of tissue occurred, used another device to complete task & 1 & 1 \\
\hline \multicolumn{4}{|l|}{ Dissection } \\
\hline 5 & Excellent dissection capability. Separate tissues, no need from another instrument & 5 & 5 \\
\hline 4 & Good. Able to dissect tissue but restricted jaw opening and/or ability to separate tissue & 4 & 4 \\
\hline 3 & Average. Difficulties at ability to dissect tissue off structures & 3 & 3 \\
\hline 2 & Fair. Limited jaw opening and/or ability to spread tissue & 2 & 2 \\
\hline 1 & Unable to effectively dissect tissue off structures & 1 & 1 \\
\hline \multicolumn{4}{|c|}{ Tissue manipulation } \\
\hline 5 & Excellent manipulation capability. Grasps and manipulate tissue without any traumatic injuries & 5 & 5 \\
\hline 4 & $\begin{array}{l}\text { Good. Manipulates tissue but re-grasping occasionally without traumatic injuries or any inju- } \\
\text { ries requiring repair }\end{array}$ & 4 & 4 \\
\hline 3 & Average. Difficult to grasp and manipulate tissue. Traumatic injuries requiring repairs & 3 & 3 \\
\hline 2 & Fair. Difficulties at grasp and manipulate tissue. Traumatic injuries requiring immediate repair & 2 & 2 \\
\hline 1 & Unable to manipulate tissue and/or cause traumatic injuries requiring immediate repair & 1 & 1 \\
\hline
\end{tabular}

Table 2 Surgeons' instrument evaluation survey

\begin{tabular}{lll}
\hline$\#$ & $\begin{array}{l}\text { Instrument } \\
\text { Device handling }\end{array}$ & Score 1 worst to 10 best \\
\hline 1 & The ease of opening and closing the handle & 12345678910 \\
2 & Ease to maneuver & 12345678910 \\
3 & Weight balance & 12345678910 \\
4 & Fatigue from the use of handle, or any pain $(1=$ max pain, & 12345678910 \\
& fatigue/10= no pain fatigue) & \\
5 & The ease in pushing the handle seal and cut buttons & 12345678910 \\
6 & The ease of turning the rotor knob & 12345678910 \\
7 & What is the level of your confidence in sealing large vessels & 12345678910 \\
8 & (more than 5 mm) & 12345678910 \\
\hline
\end{tabular}


Table 3 Drier surgical field: definitions and scores

\begin{tabular}{|c|c|c|c|}
\hline Variable score & Variable definition & THUNDERBEAT & LigaSure \\
\hline Drier surgical field & Definition of Score & & \\
\hline Variable score & Variable definition & THUNDERBEAT & LigaSure \\
\hline \multicolumn{4}{|l|}{ Drier surgical score } \\
\hline 5 & No oozing at vessel or tissue site in entire surgical field & 5 & 5 \\
\hline 4 & $\begin{array}{l}\text { Minimal/mild blood oozing at tissue site in } 1 \text { or } 2 \text { areas surgical field; no intervention } \\
\text { needed }\end{array}$ & 4 & 4 \\
\hline 3 & $\begin{array}{l}\text { Moderate blood oozing at tissue site in few areas of the surgical field and requiring inter- } \\
\text { vention }\end{array}$ & 3 & 3 \\
\hline 2 & Heavy bleeding requiring immediate further intervention at any part of the surgical field & 2 & 2 \\
\hline 1 & Heavy bleeding, hemostasis achieved with the instrument with more than two attempts & 1 & 1 \\
\hline
\end{tabular}
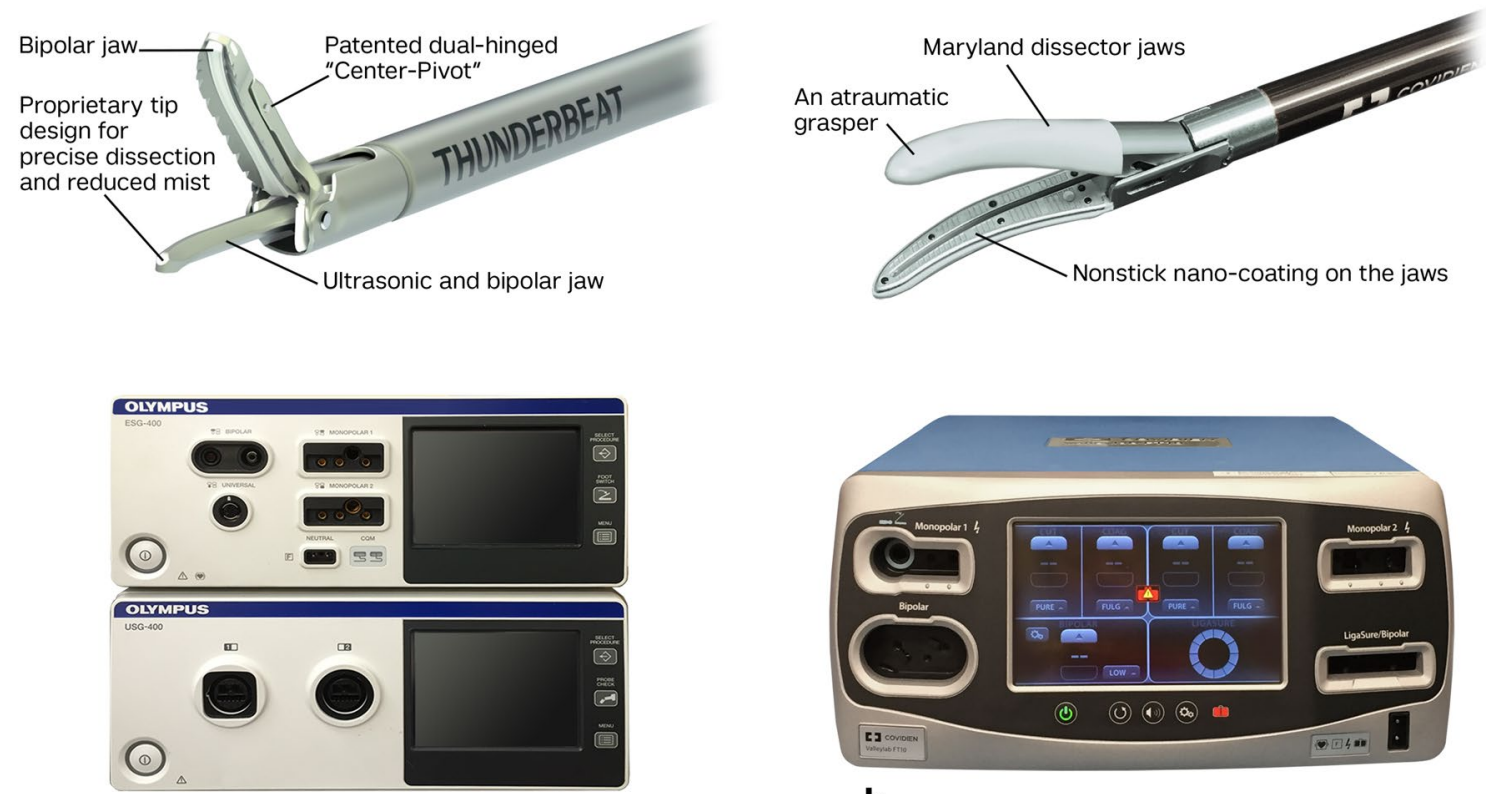

a

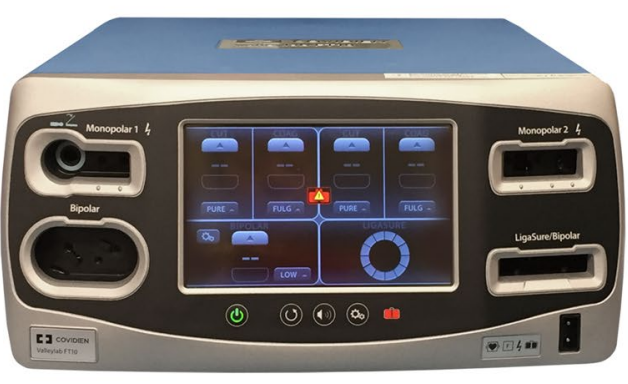

b

Fig. 2 Energy devices a THUNDERBEAT (Olympus, Japan) and b Maryland LigaSure ${ }^{\mathrm{TM}}$ (Medtronic, USA)

of the report on RCT [13]. Seventy three patients were enrolled in the study from February 2016 to April 2019, and sixty of them were randomized into the two groups: $n=31$ in Group 1: THUNDERBEAT and $n=29$ in Group 2: LigaSure and included in the analyses. The other 13 patients were withdrawn from the study prior to the randomization for variety of reasons such as surgery cancellation, change of surgical plan or change in medical conditions excluding the subjects. All patients completed the 30 days follow up time. There were no statistical differences between the two groups in terms of demographics-age, sex, BMI, ASA, preoperative diagnosis, and preoperative comorbidities (Table 4). No significant difference was found between the groups in the primary outcomes, DTSR $(p=0.214)$ and the total time of the surgical procedure $(p=0.311)$. Detailed results of the intraoperative outcomes are listed in Table 5. Significant differences in versatility overall score and in surgical segment 3 versatility score were observed between the groups, with TB device having a higher score than LigaSure device ( $p=0.045$ and 0.041 respectively). In addition, TB demonstrated significantly higher scores in tissue dissection and tissue manipulation in surgical segment 3 , and higher sealing score in segment 6 with $p=0.011,0.026$ and 0.023 , correspondingly (Table 5 ). There were no significant differences between the groups regarding the coagulation tests PT, PTT, and INR ( $p=0.463,0.122$, and 0.069 , respectively).

Postoperatively, there were no significant differences between the groups in restoration of the gastrointestinal tract, postoperative complication within 30 days, and other hospital parameters of surgical recovery (Table 6). There 
Table 4 Results: Demographics and sample characteristics

\begin{tabular}{llll}
\hline Parameter & $\begin{array}{l}\text { THUN- } \\
\text { DERBEAT } \\
n=31\end{array}$ & LigaSure $n=29$ & $p^{*}$ \\
& & & \\
\hline Age in years median (range) & $54(31-92)$ & $63(29-88)$ & 0.515 \\
Female/Male & $14 / 17$ & $17 / 12$ & 0.297 \\
BMI mean/sd & $26.3 \pm 4.3$ & $26.4 \pm 4$ & 0.965 \\
ASA median (range) & $2(2-3)$ & $2(2-3)$ & 0.923 \\
Follow up time 30 days & $31(100 \%)$ & $29(100 \%)$ & \\
Preoperative diagnosis & & & \\
Neoplasm & $11(35.5 \%)$ & $8(27.6 \%)$ & 0.511 \\
$\quad$ Diverticulitis & $20(64.5 \%)$ & $21(72.4 \%)$ & 0.511 \\
Preoperative comorbidities & & & \\
HTN & $8(25.8 \%)$ & $12(41.4 \%)$ & 0.201 \\
CAD & $4(12.9 \%)$ & $2(6.9 \%)$ & 0.438 \\
COPD & $2(6.5 \%)$ & $1(3.4 \%)$ & 0.594 \\
Diabetes & $1(3.2 \%)$ & $2(6.9 \%)$ & 0.514 \\
Others & $2(6.5 \%)$ & $1(3.4)$ & 0.514 \\
Laparoscopic left colectomy & $31(100 \%)$ & $29(100 \%)$ & \\
Converted to open surgery & $1(3.2 \%)$ & $2(6.9 \%)$ & 0.514 \\
\hline
\end{tabular}

Demographic, preoperative, and postoperative variables were compared between groups by the Wilcoxon rank-sum test for continuous variables and the $\chi^{2}$ test/Fisher's exact test for categorical variables, as appropriate

All $p$-values are two-sided with statistical significance evaluated at the $0.05 \alpha$ level, ${ }^{*} p<0.05$. BMI body mass index, ASA American Society of Anesthesiologists physical status classification, HTN hypertension, $C A D$ coronary artery disease, $C O P D$ chronic obstructive pulmonay disease

was no mortality observed. Surgeon survey results are listed in Table 7. Surgeon's overall satisfaction with the instrument was significantly higher for the THUNDERBEAT device $(p=0.015)$. LigaSure demonstrated a higher score for "less pain and less fatigue" from use the of instrument handle but it was not statistically significant $(p=0.08)$ (Table 7).

\section{Discussion}

The goal of this randomized trial was to evaluate the clinical performance between TB and Maryland LigaSure Energy Devices with primary outcome DTSR. Surgical time has become an important intraoperative factor along with safe and effective hemostasis and tissue dissection, as it is directly related to the cost-effectiveness of the surgical procedure. Development of new advanced energy based surgical instruments for laparoscopic surgery have shortened the surgical procedure time and have replaced the conventional hemostasis tools such as sutures, clips and staples with fast, safe and effective hemostasis. Our study did not find significant difference between the
TB and LigaSure devices, consistent with the finding of other recent publications [2,12]. A retrospective study from Italy compared outcomes and cost between TB and three other energy-based devices in patients undergoing laparoscopic colorectal resection, did not find any significant difference in the operative time and other outcomes between the groups [2]. Similar findings were reported by Shuradja in 2018 from a prospective study with retrospective cohort for comparison of TB to LigaSure and Harmonic Ace. The study reported no significant difference between the devices in operative time and suggested that they are equally safe and effective [12]. In our study, the 12-min difference in DTSR between the groups (higher in TB group) was neither clinically nor statistically significant. A post hoc power calculation shows that a statistically significant 12-min difference between the two groups could only be detected with a power of $24 \%$. The current study, with 30 patients per group, if adequately powered at $80 \%$, would be able to detect a difference of $27 \mathrm{~min}$ or greater between the two groups. Nonetheless, since $12 \mathrm{~min}$ may affect the cost in the operating room, the effect of the surgeon's experience with the energy device on the operative time was evaluated. We found significantly less time to specimen removal between one experienced surgeon compared to the rest of the surgeons, which may explain the 12 min difference between the groups. Since there is no significant difference between the devices in the time to specimen removal and the overall total time of the surgery, number of applications until vessel coagulation achieved, and number of instruments exchanges in/out of the abdomen, we did not conduct a cost analysis. The actual cost between the devices is also similar (TB $\$ 475$ vs. LigaSure $\$ 495)$. However, the device prices may differ between different institutions. Allaix et al. also did not find any cost difference between TB and other energy devices [11].

The versatility of the new surgical devices allowing multiple functions of the device is important for shortening the surgical time and minimizing the instruments exchange while providing safe and effective tissue dissection and vessel sealing. In order to have more objective evaluation of the clinical usefulness of the energy devices in the study, we used a "versatility score" (see methods) [4, 5]. In this study, the TB demonstrated significantly higher overall versatility score vs. LigaSure ( 4.8 vs. $4.7, p=0.045$ ), clinically inconsequential, as both instruments had high versatility scores. Two previous studies have reported significantly higher versatility score for TB device compared to other surgical devices, but this versatility difference was not reported to affect the clinical performance of the devices $[4,5]$.

The TB tip (Fig. 2a, b) allows making a swift entry into a new surgical plane, which is a technical differentiation between it and the LigaSure. Both instruments demonstrated 
Table 5 Results: Intraoperative outcomes

\begin{tabular}{|c|c|c|c|}
\hline Parameter & THUNDERBEAT $n=31$ & LigaSure $n=29$ & $p^{*}$ \\
\hline \multicolumn{4}{|l|}{ Intraoperative outcomes } \\
\hline Dissection time to specimen removal min median/range & $91(41-172)$ & $77(38-175)$ & 0.214 \\
\hline Length of surgical procedure min median/range & $176(113-270)$ & $170(98-265)$ & 0.311 \\
\hline Lysis of adhesions min median/range & $1(0-70)$ & $1(0-42)$ & 0.618 \\
\hline \multicolumn{4}{|l|}{ Versatility index scores mean/sd } \\
\hline Overall versatility score mean/sd & $4.8 \pm 0.18$ & $4.7 \pm 0.22$ & 0.045 \\
\hline Seg2 versatility score mean/sd & $4.8 \pm 0.33$ & $4.7 \pm 0.32$ & 0.147 \\
\hline Seg3 versatility score mean/sd & $4.9 \pm 0.25$ & $4.7 \pm 0.39$ & 0.041 \\
\hline Seg6 versatility score mean/sd & $4.7 \pm 0.30$ & & 0.070 \\
\hline Seg1 dissection score mean/sd & $5 \pm 0.02$ & $4.8 \pm 0.30$ & 0.580 \\
\hline Seg2 hemostasis mean/sd & $4.7 \pm 0.60$ & $4.4 \pm 0.55$ & 0.154 \\
\hline Seg2 dissection score mean/sd & $5 \pm 0.02$ & $4.9 \pm 0.41$ & 0.147 \\
\hline Seg3 hemostasis mean/sd & $4.6 \pm 0.60$ & $4.4 \pm 0.61$ & 0.168 \\
\hline Seg3 sealing mean/sd & $4.9 \pm 0.30$ & $4.7 \pm 0.51$ & 0.085 \\
\hline Seg3 cut mean/sd & $4.9 \pm 0.18$ & $4.8 \pm 0.35$ & 0.117 \\
\hline Seg3 dissection score mean/sd & $4.9 \pm 0.04$ & $4.8 \pm 0.38$ & 0.011 \\
\hline Seg3 tissue manipulation score mean/sd & $4.9 \pm 0.03$ & $4.8 \pm 0.35$ & 0.026 \\
\hline Seg 4 dissection score mean/sd & $5 \pm 0.02$ & $4.9 \pm 0.30$ & 0.067 \\
\hline Seg5 dissection score mean/sd & $5 \pm 0.02$ & $4.9 \pm 0.30$ & 0.077 \\
\hline Seg6 hemostasis mean/sd & $4.4 \pm 0.65$ & $4.2 \pm 0.66$ & 0.229 \\
\hline Seg6 sealing mean/sd & $4.8 \pm 0.40$ & $4.4 \pm 0.77$ & 0.023 \\
\hline Seg6 dissection score mean/sd & $5 \pm 0.02$ & $4.9 \pm 0.26$ & 0.101 \\
\hline Dryness of the surgical field average score mean/sd & $4.5 \pm 0.38$ & $4.4 \pm 0.33$ & 0.572 \\
\hline \multicolumn{4}{|l|}{ Vessels sealing } \\
\hline \multicolumn{4}{|l|}{ Number of applications until vessel coagulation achieved } \\
\hline Left colic artery & $2.2 \pm 0.75$ & $2 \pm 1$ & 0.930 \\
\hline Sigmoid arteries & $2.4 \pm 1.5$ & $2.6 \pm 1.3$ & 0.469 \\
\hline Superior rectal arteries & $2.7 \pm 1.3$ & $2.9 \pm 1.2$ & 0.316 \\
\hline IMA/IMV & $3.1 \pm 0.9$ & $4.5 \pm 3.7$ & 0.866 \\
\hline Success of sealing & $29(93.5 \%)$ & $27(93.1 \%)$ & 0.945 \\
\hline Bleeding at time of sealing & $3(9.7 \%)$ & $4(13.8 \%)$ & 0.620 \\
\hline Bleeding mesentery dissection & $4(12.9 \%)$ & $7(24.1 \%)$ & 0.261 \\
\hline $\mathrm{EBL}(\mathrm{ml})$ & $87 \pm 97$ & $66.4 \pm 64$ & 0.419 \\
\hline Intraoperative blood transfusion & 0 & 0 & 1 \\
\hline Intraoperative complications other except bleeding & 0 & 1 & 0.760 \\
\hline Intraoperative complication related to the devices & 0 & 0 & 1 \\
\hline Number of instruments exchanges in/out of abdomen & $1.9 \pm 1.2$ & $1.38 \pm 1.26$ & 0.117 \\
\hline
\end{tabular}

All $p$-values are two-sided with statistical significance evaluated at the $0.05 \alpha$ level, ${ }^{*} p<0.05$; Seg segment, IMA inferior mesenteric artery, IMV inferior mesenteric vein, $E B L$ estimated blood loss in $\mathrm{ml}$

safe and effective clinical performance in vessel sealing of left colic artery, sigmoid arteries, superior rectal arteries and large vessels such as IMA and IMV. There was no significant difference in the number of applications until vessel coagulation was achieved for sealing of all vessels including IMA and IMV. In two cases, with calcified vessels (one in TB group and one in LigaSure group), the numbers of applications were higher, and clips had to be used to achieve vessel sealing and hemostasis. This is an important concept in all compression energy devices.

One of the main concerns when working with ultrasonic energy is thermal spread. With TB and other energy devices like Harmonic Ace (Johnson \& Johnson), there is a high temperature at the vibrating jaws, which can reach up $200^{\circ} \mathrm{C}$ compared to $100{ }^{\circ} \mathrm{C}$ in bipolar instruments, theoretically increasing the risk of thermal injuries [4, 14]. Seehofer et al. 
Table 6 Results: Postoperative outcomes

\begin{tabular}{|c|c|c|c|c|}
\hline Parameter & $\begin{array}{l}\text { THUNDERBEAT } \\
n=31\end{array}$ & LigaSure $n=29$ & $p^{*}$ & \\
\hline \multicolumn{5}{|l|}{ GI recovery } \\
\hline First flatus POD day median (range) & $2(1-4)$ & $2(1-4)$ & 0.733 & \\
\hline First bowel movement POD day median (range) & $2(1-5)$ & $2.5(1-4)$ & 0.835 & \\
\hline First solid food POD day median (range) & $2(1-8)$ & $2(1-4)$ & 0.199 & \\
\hline Postoperative complications 30 days & & & & Clavien-Dindo Grade \\
\hline Delayed thermal injuries related to energy devices & 0 & 0 & 1 & - \\
\hline Postoperative rectal bleeding & $3(9.7 \%)$ & $4(13.8 \%)$ & 0.620 & $\begin{array}{l}\text { Grade IIIa-1 } \\
\text { Grade IIIb-6 }\end{array}$ \\
\hline Anastomotic leak & 0 & $2(6.9 \%)$ & 0.137 & $\begin{array}{l}\text { Grade IIIa-1 } \\
\text { Grade IIIb-1 }\end{array}$ \\
\hline Postoperative ileus & $1(3.2 \%)$ & 0 & 0.329 & Grade II-1 \\
\hline Wound hematoma incision & $1(3.2 \%)$ & $3(10.3)$ & 0.269 & Grade I-4 \\
\hline UTI & $1(3.2 \%)$ & 0 & 0.329 & \\
\hline \multicolumn{5}{|l|}{ Hospital parameters } \\
\hline LOHS in day mean/sd & $4.5 \pm 3.2$ & $5.3 \pm 3.9$ & 0.272 & \\
\hline LOSS in days mean/sd & $4.5 \pm 3.1$ & $5.3 \pm 3.9$ & 0.265 & \\
\hline Reoperation & $2(6.5 \%)$ & $4(13.8 \%)$ & 0.344 & \\
\hline Readmission & $1(3.2 \%)$ & 0 & 0.329 & \\
\hline Mortality & 0 & 0 & 1 & \\
\hline
\end{tabular}

All $p$-values are two-sided with statistical significance evaluated at the $0.05 \alpha$ level, $* p<0.05$

LOHS length of hospital stay from admission to hospital discharge, LOSS length of postsurgical stay from day of surgery to hospital discharge, UTI urinary tract infection

Table 7 Results: Surgeons survey

\begin{tabular}{llcc}
\hline Instrument & $\begin{array}{l}\text { THUNDER- } \\
\text { BEAT } n=31\end{array}$ & LigaSure $n=29$ & $p$ \\
\hline Device handling & & & \\
$\quad$ Ease of opening and closing the handle & $8.5 \pm 1$ & $7.7 \pm 1.2$ & 0.012 \\
$\quad$ Ease to maneuver & $8.5 \pm 0.9$ & $7.7 \pm 1.1$ & $<0.0001$ \\
$\quad$ Weight balance & $8.6 \pm 0.7$ & $8.3 \pm 0.9$ & 0.104 \\
$\quad$ Fatigue from the use of handle, or any pain (1=max & $8.5 \pm 1.6$ & $9.2 \pm 1.1$ & 0.08 \\
$\quad$ pain, fatigue/10= no pain fatigue) & & & 0.007 \\
$\quad$ The ease in pushing the handle seal and cut buttons & $8.2 \pm 1.3$ & $7.2 \pm 1.5$ & 0.089 \\
$\quad$ Ease of turning the rotor knob & $7.6 \pm 1.6$ & $7.0 \pm 1.4$ & 0.31 \\
$\quad$ What is the level of your confidence in sealing large & $8.8 \pm 1.5$ & $8.4 \pm 1.6$ & \\
$\quad$ vessels (more than 5 mm) & & & 0.015 \\
Overall satisfaction & $8.5 \pm 1.1$ & $7.8 \pm 1$ & \\
\hline
\end{tabular}

using a Thermocamera reported that after repeated activation TB reaches $172 \pm 7{ }^{\circ} \mathrm{C}$, and 60 seconds are needed to decline to a safer $60 \mathrm{C}[15,16]$. Despite these data, no intraoperative or postoperative delayed thermal injuries occurred in our study.

This study also evaluated the "dryness" of the surgical field, assessing for generalized oozing during mesenteric and vessel dissection, and lysis of adhesions [17]. Both groups had similar scores (Table 5). Patient's coagulation factors PT, PTT and INR were evaluated prior to surgery, and patients on anticoagulants prior to surgery or coagulopathy disorders were excluded from the study in order not to affect the instruments hemostasis and sealing evaluation. During surgery all patients had warm air blanket and were well monitored for hypothermia.

Postoperatively, the groups did not differ significantly in complication rates. Three patients in Group 1 and four in Group 2 experienced rectal bleeding not related to the energy devices but rather to the intestinal anastomosis. No patients experienced abdominal bleeding postoperatively 


\begin{tabular}{|c|c|c|}
\hline & Pros & Cons \\
\hline THUNDERBEAT & $\begin{array}{l}\text { - } \text { Rapid tissue entry due to the tip } \\
\text { - } \text { Precise grasping at tip } \\
\text { - } \text { Rapid cut and seal } \\
\text { - } \text { Offers combine bipolar and } \\
\text { ultrasonic energy }\end{array}$ & $\begin{array}{l}\text { - Tip is hot } \\
\text { - No cold cutting }\end{array}$ \\
\hline LigaSure Maryland & $\begin{array}{l}\text { Tip protected/coated } \\
\text { polycarbonate } \\
\text { - Long time on market } \\
\text { - Rapid cut and seal } \\
\text { - "Cold cutting" }\end{array}$ & $\begin{array}{l}\text { - Can't grasp tissue at tip } \\
\text { - Weak jaw shaft } \\
\text { - Dense tissue difficult to } \\
\text { compress }\end{array}$ \\
\hline
\end{tabular}

Fig. 3 Useful tips for technical aspects of using THUNDERBEAT and LigaSure

requiring reoperation. One patient required transfusion postoperatively following rectal bleeding from their anastomosis. Two patients were treated for anastomotic leak and recovered successfully, with one requiring reoperation and temporary stoma. Neither event appeared to have any relation to use of an energy device.

Surgeon's overall satisfaction with the instruments showed a significant preference for the TB regarding ease of opening and closing the handle, ease to maneuver the instrument, and the ease in pushing the handle seal and cut buttons (Table 7). Less fatigue and pain were reported with the LigaSure, but it was not statistically significant. While the survey was designed to evaluate the surgeon's satisfaction with the energy devices, the results are surely influenced by the surgeon's individual preference and experience, as only five surgeons participated in the study and half of the patients were operated on by one experienced surgeon. Therefore, the significant difference between the groups should not be interpreted as clinically important or be generalized to other surgeons' experience with LigaSure or TB energy devices. However, this information may be useful for improvement of the device's features. A few pros and cons about the technical aspect of the devices are presented in Fig. 3.

Limitations of the study include the following:

(1) It was conducted in a single academic institution with highly experienced colorectal surgeons in laparoscopy and surgical energy devices.

(2) The study used the Maryland LigaSure Energy Device for comparison, which also was a new device at that time this study was designed. It is possible that other style LigaSure energy devices (e.g., blunt tipped) may have performed better than the one used in this study.
(3) At the time we embarked on this study, there were no other studies in colorectal surgery evaluating THUNDERBEAT to use for estimation of dissection time. Post hoc analysis was performed to compare the DTSR between the groups, thus the results from this study may not be generalizable.

In summary, the TB and LigaSure devices compared in this randomized trial did not show significant difference between the study groups in the primary outcome, time to specimen removal. No patient in either group had any complication related to the energy devices, most importantly bleeding or thermal injury. A versatility score comparing the instruments is significantly different favoring $\mathrm{TB}$, but not clinically significant as both groups have very high versatility scores. The study did not find any significant difference in intraoperative or postoperative complications or any complications related to the energy devices.

In conclusion, in a randomized control trial comparing THUNDERBEAT and LigaSure compressive energy devices, both were effective and safe in dividing soft tissue and sealing mesenteric blood vessels during laparoscopic left colon surgery, with THUNDERBEAT demonstrating some advantages over LigaSure during omental dissection and tissue manipulation.

Acknowledgements The authors would like to thank and acknowledge that this study was supported by Research Grant from Olympus. Also, the authors thank the medical illustrator Yuko Tonohira for drawing the procedure illustration.

Author contributions Conception and design: JWM, KT, PJS, PC, KG. Acquisition of data: JWM, KT, PJS, KG, MPP, KM. Analysis and interpretation of data: KT, PC, JWM, PJS, KG. Drafting the article or revising it critically for important intellectual content: KT, JWM, PC, 
PJS, KG, MPP, KM. Final approval of the version to be published: JWM, KT, PC, PJS, KG, MPP, KM.

\section{Declarations}

Disclosures This study was investigator-initiated and industry sponsored trial. supported by Research Grant from Olympus. The authors Koianka Trencheva, Dr. PH, MS, Kota Momose, MD, Miroslav P. Peev, MD, Paul Christos, Dr. PH, MS, Parul J. Shukla, MD, and Kelly Garrett, MD have no conflicts of interest or financial ties to disclose. Dr. Jeffrey Milsom was the primary investigator receiving the Olympus Grant and has had a consulting agreement with Olympus in the past.

Open Access This article is licensed under a Creative Commons Attribution 4.0 International License, which permits use, sharing, adaptation, distribution and reproduction in any medium or format, as long as you give appropriate credit to the original author(s) and the source, provide a link to the Creative Commons licence, and indicate if changes were made. The images or other third party material in this article are included in the article's Creative Commons licence, unless indicated otherwise in a credit line to the material. If material is not included in the article's Creative Commons licence and your intended use is not permitted by statutory regulation or exceeds the permitted use, you will need to obtain permission directly from the copyright holder. To view a copy of this licence, visit http://creativecommons.org/licenses/by/4.0/.

\section{References}

1. Targarona EM, Balague C, Marin J et al (2005) Energy sources for laparoscopic colectomy: a prospective randomized comparison of conventional electrosurgery, bipolar computer-controlled electrosurgery and ultrasonic dissection. Operative outcome and costs analysis. Surg Innov 12:339-344

2. Allaix ME, Arezzo A, Giraudo G, Arolfo S, Mistrangelo M, Morino M (2017) The THUNDERBEAT and other energy devices in laparoscopic colorectal resections: analysis of outcomes and costs. J Laparoendosc Adv Surg Tech 27:1225-1229

3. Devassy R, Hanif S, Krentel H, Verhoeven HC, Torres-de la Roche LA, De Wilde RL (2019) Laparoscopic ultrasonic dissectors: technology update by a review of literature. Med Devices (Auckl NZ) 12:1

4. Milsom J, Trencheva K, Monette S, Pavoor R, Shukla P, Ma J, Sonoda T (2012) Evaluation of the safety, efficacy, and versatility of a new surgical energy device (THUNDERBEAT) in comparison with Harmonic ACE, LigaSure V, and EnSeal devices in a porcine model. Laparoendosc Adv Surg Tech A 22(4):378-386

5. Milsom JW, Trencheva K, Sonoda T, Nandakumar G, Shukla PJ, Lee S (2015) A prospective trial evaluating the clinical performance of a novel surgical energy device in laparoscopic colon surgery. Surg Endosc 29(5):1161-1166

6. Bergamaschi R, Yavuz Y, Marvik R (2003) Laparoscopic bowel resection: a comparison of three ultrasonically activated devices. JSLS 7(1):19-22

7. Gossot D, Buess G, Cuschieri A et al (1999) Ultrasonic dissection for endoscopic surgery. The E.A.E.S. Technology Group. Surg Endosc 13(4):412-417

8. Campbell PA, Cresswell AB, Frank TG et al (2003) Real-time thermography during energized vessel sealing and dissection. Surg Endosc 17(10):1640-1645

9. Takada M, Ichihara T, Kuroda Y (2005) Comparative study of electrothermal bipolar vessel sealer and ultrasonic coagulating shears in laparoscopic colectomy. Surg Endosc 19(2):226-228

10. Campagnacci R, de Sanctis A, Baldarelli M et al (2007) Electrothermal bipolar vessel sealing device vs. ultrasonic coagulating shears in laparoscopic colectomies: a comparative study. Surg Endosc 21(9):1526-1531

11. Allaix ME, Furnée EJ, Arezzo A, Mistrangelo M, Morino M (2016) Energy sources for laparoscopic colorectal surgery: is one better than the others? J Laparoendosc Adv Surg Tech 26(4):264-269

12. Suhardja TS, Norhadi S, Ee E, Hodgkins B (2018) Comparison of the THUNDERBEAT and other energy devices in laparoscopic colorectal resection: a single-center experience. J Laparoendosc Adv Surg Tech 28(12):1417-1421

13. Grant S, Mayo-Wilson E, Montgomery P et al (2018) CONSORTSPI 2018 Explanation and Elaboration: guidance for reporting social and psychological intervention trials. Trials 19:406. https:// doi.org/10.1186/s13063-018-2735-z

14. Ceccanti S, Falconi I, Frediani S, Boscarelli A, Catani M, Cozzi DA (2017) The THUNDERBEAT system for tissue dissection and vascular control in laparoscopic splenectomy. Minim Invasive Ther Allied Technol 26(4):249-252

15. Seehofer D, Mogl M, Boas-Knoop S, Unger J, Schirmeier A, Chopra S, Eurich D (2012) Safety and efficacy of new integrated bipolar and ultrasonic scissors compared to conventional laparoscopic 5-mm sealing and cutting instruments. Surg Endosc 26(9):2541-2549

16. Kwak HY, Dionigi G, Kim D, Lee HY, Son GS, Lee JB et al (2016) Thermal injury of the recurrent laryngeal nerve by THUNDERBEAT during thyroid surgery: findings from continuous intraoperative neuromonitoring in a porcine model. J Surg Res 200(1):177-182

17. Rajagopalan S, Mascha E, Na J, Sessler DI (2008) The effects of mild perioperative hypothermia on blood loss and transfusion requirement. Anesthesiology: J Am Soc Anesthesiol 108(1):71-77

Publisher's Note Springer Nature remains neutral with regard to jurisdictional claims in published maps and institutional affiliations. 